\section{Linnean shortfall still a major concern in India: as evident by the micromoth family Tortricidae (Lepidoptera)}

\author{
Santhosh Naik, P. R. Shashank*, N. N. Rajgopal \\ and Naresh M. Meshram \\ National Pusa Collection, Division of Entomology, ICAR-Indian \\ Agricultural Research Institute, Pusa, New Delhi 110 012, India
}

Anthropogenic activities influence rapid environmental changes on earth and the reality of climate change is a significant feature in implementing conservation action plans in many countries. The knowledge of biodiversity data is an increasingly important source of information in studies of biogeography and conservation. Presence of temporal, spatial and taxonomical gaps in biodiversity documentation is a major concern. One of the major gaps or shortfalls is the lack of taxonomic work, i.e. species descriptions called Linnean shortfall. Here we evaluate patterns of species description in a major micromoth family Tortricidae from India during 1775 to 2018 . We found that a total of 392 species of tortricid moths have been described from the country. Among all the authors who have contributed to the species description, eight have described more than $85 \%$ of tortricid species from India. The cumulative curve of the tortricid species described showed the highest peak during 1901-1925, wherein 226 species were described from the country. Among the biogeographic zones, the North East Zone recorded the highest species descriptions $(47.19 \%)$ followed by the Deccan Peninsula (10.71\%). Our analysis shows Linnean shortfall in this group and the taxonomic expeditions are skewed towards only a few regions. Accordingly, practices to increase taxonomic expeditions, including increased funding in exploratory research and increasing species discovery rate are the need of the hour in many insect groups.

Keywords: Biogeographic zones, conservation, shortfalls in biodiversity, species description, tortricid moths.

THE earth is undergoing rapid environmental changes due to anthropogenic activities. As most of the scientific community considers climate change to be real ${ }^{1}$, the priority of implementing conservation action plans is indispensable for many countries. Researchers on biodiversity around the world are dealing with very large data from the past decade. However, our knowledge about biodiversity is still inadequate and we are uncertain about how many species there are on our planet; and for those species described, knowledge about their ecology and distribution is scanty. These gaps or shortfalls can be linked to the lack of taxonomic work, i.e. species descrip-

\footnotetext{
*For correspondence. (e-mail: spathour@gmail.com)
}

tions called Linnean shortfall ${ }^{2}$, or absence of data regarding their distribution, i.e. Wallacean shortfall ${ }^{3}$, or data on species abundance and population dynamics in space and time, i.e. Prestonian shortfall ${ }^{4}$. Together these lead to a fourth gap in our knowledge, i.e. the lack of information on phylogenetic relationships and thus on the evolutionary history of life on earth known as Darwinian shortfall ${ }^{5}$. Recently, another three new shortfalls have been proposed, viz. Raunkiæran (lack of knowledge about species traits and their ecological functions), Hutchinsonian (lack of knowledge about the responses and tolerances of species to abiotic conditions) and Eltonian (lack of knowledge on species interactions and the effects of these interactions on the survival and fitness of individuals) by Hortal et $a l .{ }^{6}$ with a general framework for the combined impacts and consequences of shortfalls of large-scale biodiversity knowledge for evolutionary and ecological research.

India is one of the signatories of the Convention on Biological Diversity with specific goals to be achieved through national strategies, plans or programmes for conservation and sustainable use of biodiversity. The conservation actions and assessments rely on priority setting due to paucity of time and funding ${ }^{7}$. Any conservation effort will start with assessing species or taxonomic groups which are threatened worldwide. However, many developing countries are planning to prepare a fresh priority list of species for conservation efforts. The major hindrances in global conservation status assessment are the so-called Linnean and Wallacean shortfalls, as demonstrated by Whittaker et al. ${ }^{8}$. Lepidoptera (moths and butterflies) conservation in recent years has grown from an arcane topic to everyday concern ${ }^{9}$. In India, awareness on conservation of butterflies and some macromoths is gaining momentum ${ }^{10}$. However, numerous smaller moths have been largely ignored; this may be due to limited taxonomic studies in these groups. To understand the status of taxonomic studies in micromoths, we have selected the family Tortricidae.

Tortricidae includes over 1000 genera and nearly 10,000 named species in the world ${ }^{11}$. Tortricidae is the only family under the superfamily Tortricoidea. Tortricoidea is second only to the Gelechioidea in species diversity within the micromoths ${ }^{12}$. They are diverse and abundant components of tropical, subtropical and temperate forest ecosystems, and are economically significant because many species are pests of agriculturally important crops $^{13}$. However, there are no data on Indian Tortricidae, except the world checklist in which many species from India are not included ${ }^{14}$. The main purpose of the present study is to reveal pattern of species description of family Tortricidae from India.

The relevant articles related to description of tortricid moths from India were collected using different data sources, viz. world catalogues, checklists, zoological records, CABI Abstracts, biological abstracts and isolated 


\section{RESEARCH COMMUNICATIONS}

publications in scientific journals. Online databases on Lepidoptera such as FUNET database ${ }^{15}$, T@RTS and Eurasian Tortricid 2.0 (ref. 16) were used to compile the preliminary list. Further, from each description record type locality data have been extracted. These data are used to analyse tortricid species reported from different biogeographic zones of India. Data were refined by checking descriptions of individual species, synonyms of type localities and present status from the period 1775 to 2018 (Figure 1). We calculated the rate of species description in a specific time period and determined the contribution of different authors to the taxonomy of Indian Tortricidae. Geographic positioning system (GPS) coordinates of type location were extracted through Google Earth by providing the longitude and latitude of each species. The GPS coordinates have been used to develop species description map using ArcGIS software (Environmental Systems Research Institute, 2018) and shape files provided by C. Sudhakar Reddy (National Remote Sensing Centre, Hyderabad, India). We have used the biogeographic classification of India according to Reddy et al. ${ }^{17}$ which recognizes 11 biogeographic zones with the Himalaya as two zones, i.e. Western Himalaya and Eastern Himalaya.

In the present study the compiled species described from India are divided into recognized 11 biogeographic zones. The results of the analysis indicate that the described species are not evenly distributed among different biogeographic zones, but are found in clusters (Figure 2). The species description pattern is skewed towards the North East zone with 185 species, which is $47.19 \%$ of the total described species. This is followed by Deccan (42 species, i.e. $10.71 \%$ ), Gangetic Plains (39 species, i.e. 9.95\%) and Western Himalaya (32 species, i.e. 8.16\%). There is no record of tortricid species described from the Desert zone (Table 1). We have mapped the description pattern of species using ARCGIS software and the results show typical hotspots on the biogeographic map (Figure 2).

Analysis of authors and the number of described species shows that maximum number of species (265) was

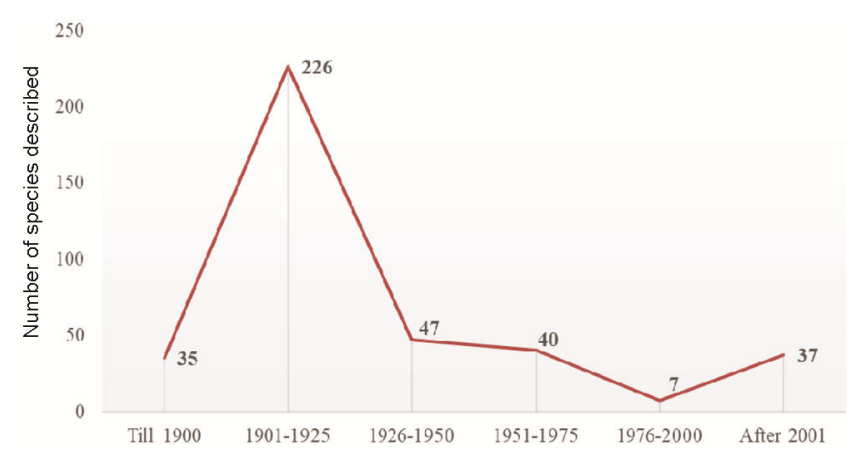

Figure 1. Number of tortricid species described between 1775 and 2018 from India. described by Edward Meyrick, comprising $67.60 \%$ of the Indian tortricids. The other important contributors were Jozef Razowski (37 species), Alexey Nikolaievich Diakonoff (26 species), H. S. Rose and H. S. Pooni (14 species) and Walsingham (10 species). There are several authors who have published individual species. Overall, the number of species described by the authors is skewed (Table 2).

Pre-1900, 35 species have been described which shows the contribution of early workers. However, post-1900 can be considered as an active period of tortricid descriptions.

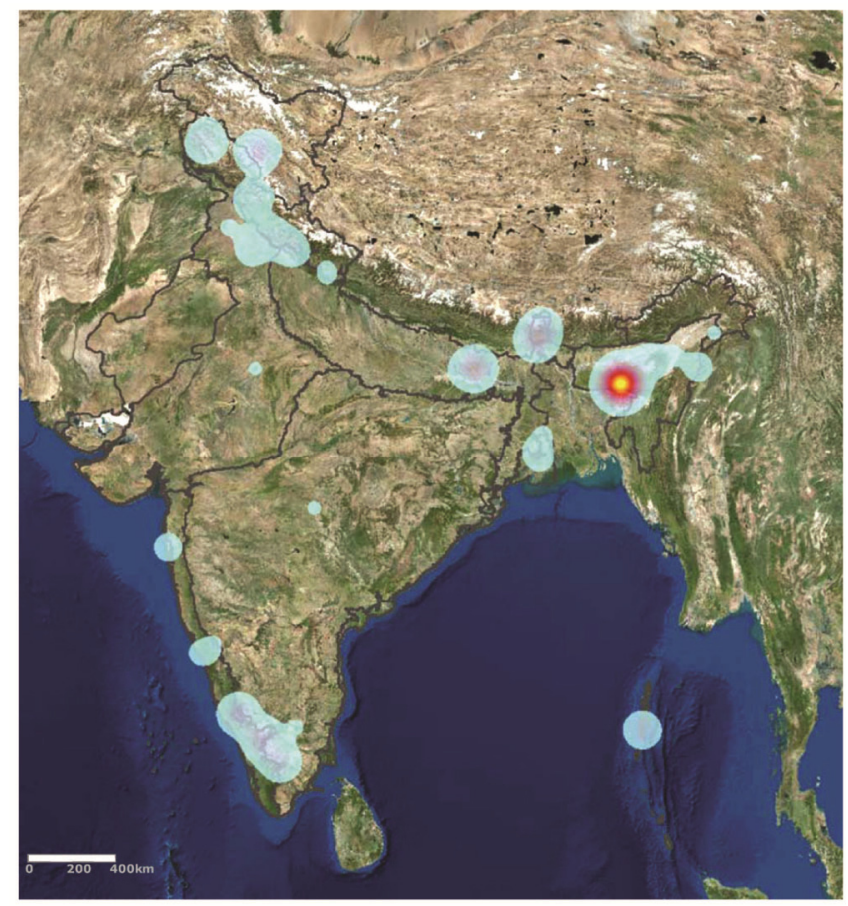

Figure 2. Map showing hotspots of tortricid species described across India. (Black outline indicates biogeographic zones; intensity of colour from light blue to red indicates concentration of species in a particular location.)

Table 1. Comparison of the number of the species from different biogeographic zones of India

\begin{tabular}{lcc}
\hline $\begin{array}{l}\text { Biogeographic } \\
\text { zone }\end{array}$ & $\begin{array}{c}\text { Number of species } \\
\text { described }\end{array}$ & $\begin{array}{c}\text { Percentage of total } \\
\text { species }\end{array}$ \\
\hline Trans Himalaya & 23 & 5.87 \\
Western Himalaya & 32 & 8.16 \\
Eastern Himalaya & 25 & 6.38 \\
North East & 185 & 47.19 \\
Gangetic Plains & 39 & 9.95 \\
Coasts & 10 & 2.55 \\
Semiarid & 10 & 2.55 \\
Desert & 0 & 0.00 \\
Western Ghats & 17 & 4.34 \\
Deccan & 42 & 10.71 \\
Islands & 09 & 2.30 \\
Total & 392 & \\
\hline
\end{tabular}


Table 2. Authors' contribution towards description of tortricid species from India

\begin{tabular}{lc}
\hline Authors & Number of species described \\
\hline Alexey Nikolaievich Diakonoff & 26 \\
Edward Meyrick & 265 \\
Nicholas Serjeevich Obraztsov & 4 \\
H. S. Pooni and H. S. Rose & 4 \\
Jozef Razowski & 37 \\
H. S. Rose and H. S. Pooni & 14 \\
Francis Walker & 9 \\
Walsingham & 10 \\
Others & 23 \\
Total & 392 \\
\hline
\end{tabular}

During 1901-25, a total of 226 species comprising $57.65 \%$ of the total Indian Tortricidae were described. Later, the species description rate showed a decreasing trend till 1976-2000 (only seven species during this period). After 2001, there was a sudden spike in the species descriptions from India (Figure 1).

The species conservation actions and assessments rely on priority setting due to paucity of time and funding. The awareness on conservation of Lepidoptera, especially macromoths and butterflies is evident in some parts of India. Nevertheless, there are numerous micromoth families which are not even documented scientifically in the country. In the present study, we specially focused on understanding taxonomic explorations in terms of species descriptions. This will be an ideal case study to adopt in other groups.

Studies on assessing species description pattern of tortricids in India revealed that the described species were not evenly distributed amongst biogeographic zones of the country. The North East zone contributed to nearly $47.19 \%$ of total species described followed by Deccan (42 species and constituting 10.71\%), Gangetic Plains (39 and $9.95 \%$ ) and Western Himalaya (32 and 8.16\%); there was no species described from the Desert zone. This may be mainly due to the colonization of British entomologists, who had contributed to the collection of these species. The results show that the description of species is more from a few isolated regions, and explorations from other biodiversity-rich regions are lacking. The number of species described peaked during 1901-1925, i.e. 226 species comprising $57.65 \%$ of the total species described from the country. This is because during that period Meyrick published many papers on Indian microlepidoptera ${ }^{18}$. The rate of species description was very low during 1976-2000. This may be due to lack of taxonomic expertise during that period. After 2000, once again there has been an increase due to the contribution of Rose and Pooni. However, the number of tortricid moths described per author shows a decline in recent years, and this is true in recent studies reported in other groups as well ${ }^{19}$. Our results indicate that tortricid moths show Linnean short- fall (lack of taxonomic work, i.e. species descriptions) in the Indian context. This can be addressed by more taxonomic expeditions and trained taxonomists. Similar results were presented by Gaston et $a l^{20}$ on geometrid moths of the Neotropical region. Our results also indicate that a relatively less number of taxonomists contributed to more number of described species, which was skewed towards specific locations. This shows that few professional taxonomists played an important role in the discovery of tortricid moths in India.

In conclusion, biodiversity research around the world and in India for specific groups of insects (ants and root grubs) is advancing towards mapping species at the grid level $^{21}$. However, species-rich and economically important groups like order Lepidoptera are still under-explored in India. This is evident from our results indicating Linnean shortfall in the important micromoth family Tortricidae. Such studies in other groups of insects will also highlight the status of taxonomic work undertaken till now and suggest data deficiency in biodiversity. This will in turn help taxonomists and biodiversity researchers to focus on areas of known data-deficiency, conservation priorities and strategies for improving biodiversity research to unravel new species and help address the Linnean shortfall.

1. Tylianakis, J. M., Didham, R. K., Bascompte, J. and Wardle, D. A., Global change and species interactions in terrestrial ecosystems. Ecol. Lett., 2008, 11, 1351-1363.

2. Brown, J. H. and Lomolino, M. V., Biogeography, Sinauer Associates, Sunderland, MA, USA, 1998, 2nd edn.

3. Bini, L. M., Diniz-Filho, J. A. F., Ranger, T. F. L. V. B., Bastos, R. P. and Plaza Pinto, M., Challenging Wallacean and Linnean shortfalls: knowledge gradients and conservation planning in a biodiversity hotspot. Divers. Distrib., 2006, 12, 475-482.

4. Cardoso, P., Erwin, T. L., Borges, P. A. and New, T. R., The seven impediments in invertebrate conservation and how to overcome them. Biol. Conserv., 2011, 144(11), 2647-2655.

5. Diniz-Filho, J. A. F., Loyola, R. D., Raia, P., Mooers, A. O. and Bini, L. M., Darwinian shortfalls in biodiversity conservation. Trends Ecol. Evol., 2013, 28(12), 689-695.

6. Hortal, J., de Bello, F., Diniz-Filho, J. A. F., Lewinsohn, T. M., Lobo, J. M. and Ladle, R. J., Seven shortfalls that beset large-scale knowledge of biodiversity. Annu. Rev. Ecol. Evol. Syst., 2015, 46, 523-549.

7. Kozlowski, G., Is the global conservation status assessment of a threatened taxon a utopia? Biodivers. Conserv., 2008, 17(3), 445448 .

8. Whittaker, R. J., Araujo, M. B., Jepson, P., Ladle, R. J., Watson, J. E. M. and Willis, K. J., Conservation biogeography: assessment and project. Divers. Distrib., 2005, 11, 3-23.

9. New, T. R., Moths (Insecta: Lepidoptera) and conservation: background and perspective. J. Insect Conserv., 2004, 8(2), 79-94.

10. Dolia, J., Devy, M. S., Aravind, N. A. and Kumar, A., Adult butterfly communities in coffee plantations around a protected area in the Western Ghats, India. Anim. Conserv., 2008, 11(1), 26-34.

11. Baixeras, J., Brown, J. W. and Gilligan, T. M., T@RTS: online world catalogue of the Tortricidae, version 1.4.0., 2010; http://www.tortricidae.com/catalogue.asp

12. Horak, M., Olethreutine moths of Australia (Lepidoptera: Tortricidae). Monogr. Aust. Lepid., 2006, 10, 522. 
13. Van der Geest, L. P. and Evenhuis, H. H., Tortricid Pests: Their Biology, Natural Enemies and Control, Elsevier, Amsterdam, 1991, p. 808.

14. Brown, J. W., World Catalogue of Insects, Volume 5: Tortricidae (Lepidoptera), Apollo Books, Stenstrup, Denmark, 2005, p. 741.

15. Savela, M., Lepidoptera and some other life forms, 2015; FUNET database - http://www.nic.funet.fi/pub/sci/bio/life/insecta/lepidoptera/ (accessed on 6 September 2018).

16. Meijerman, L. and Ulenberg, S. A., Arthropods of economic importance: Family Tortricidae Leafrollers: Eurasian Tortricidae. Zoological Museum, University of Amsterdam, The Netherlands, 2000 .

17. Reddy, C. S., Jha, C. S., Diwakar, P. G. and Dadhwal, V. K., Nationwide classification of forest types of India using remote sensing and GIS. Environ. Monit. Assess., 2015, 187(12), 1-30.

18. Meyrick, E., Descriptions of Indian microlepidoptera. J. Bombay Nat. Hist. Soc., 1912, 22, 160-182.

19. Deng, J., Li, K., Chen, C., Wu, S. and Huang, X., Discovery pattern and species numberof scale insects (Hemiptera: Coccoidea). Peer J, 2016, 4, e2526.

20. Gaston, K. J., Scoble, M. J. and Crook, A., Patterns in species description: a case study using the Geometridae (Lepidoptera). Biol. J. Linn., 1995, 55(3), 225-237.

21. Musthak Ali, T. M. and Ganeshaiah, K. N., Mapping diversity of ants and root grubs. Curr. Sci., 1998, 75(3), 201-204.

ACKNOWLEDGEMENTS. We acknowledge DST-SERB Core Research Grant (No. CRG/2018/000753) for funding this research work. This work is also a part of the Master's thesis submitted to Indian Agricultural Research Institute (IARI), New Delhi. We thank the Head, Division of Entomology, and the administration of IARI for support.

\section{Ethnic study on bastenga, a fermented bamboo shoot product of Nagaland, India}

\author{
Lydia Yeptho*, T. Ajungla and \\ Keviphruonuo Kuotsu \\ Department of Botany, Nagaland University, Lumami 798 627, India
}

Bamboo shoots are a local delicacy among the Naga tribe of Nagaland, India and the art of fermentation methods marks the ethnic diversity within the region. Bastenga, a fermented bamboo shoot product of Nagaland celebrates its existence in the culinary practice of tribal homes and forms an integral part of their livelihood. Womenfolk representing various tribes from different parts of the state were interviewed through questionnaires to document the traditional methods of preparation of bastenga by the various tribes. The ethnic tradition built around bastenga involves men

*For correspondence. (e-mail: yeptholydia@gmail.com) collecting tender shoots from the wild whereas the preparation involves women and children. The traditional knowledge is mostly passed from mothers to their daughters. The indigenous method of preparation varies among the different tribes, while most methods overlap. Data on gastronomy provide cumulative information across the state. The tribal communities share a common gastronomy, which further contributes to the socio-economic and cultural ethnicity of the region.

Keywords: Bamboo shoot, ethnic diversity, fermentation methods, traditional method, tribal communities.

BAMBOO serves as a minor forest produce that sustains the livelihood of tribal communities ${ }^{1}$ and the diverse use of bamboos connects the biodiversity and livelihood of a region $^{2}$. India accounts for the second largest bamboo reserve in the world and about $14 \mathrm{mha}$ is occupied by bamboo forests ${ }^{3}$. Within India, the North East states, viz. Arunachal Pradesh, Assam, Meghalaya, Manipur, Mizoram, Nagaland, Sikkim and Tripura, harbour the greatest bamboo diversity. About 58 species belonging to 18 genera are recorded in this region ${ }^{4}$. Nagaland lies between $25^{\circ} 06^{\prime}-27^{\circ} 04^{\prime} \mathrm{N}$ lat. and $93^{\circ} 20^{\prime}-95^{\circ} 15^{\prime} \mathrm{E}$ long., and covers an area of $16,579 \mathrm{~km}^{2}$. The bamboo forest cover area in this state is $4902 \mathrm{~km}^{2}$ (ref. 3) and the chief form of subsistence agriculture is shifting cultivation. Bamboo shoots are a common local delicacy in Nagaland. Some species of bamboo which are used as edible shoots are Bambussa bambos, Bambusa balcooa, Bambussa tulda, Chimonobambusa callosa, Dendrocalamus hamiltoni, Dendrocalamus hookeri, Dendrocalamus giganteus and Melocanna baccifera ${ }^{5}$. Bamboo shoots are harvested during the months of June to October and are consumed as tender shoots, sun-dried, fermented or made into pickles. Very few reports are available on the potential production, market availability and cost-benefit analysis survey of edible bamboo species ${ }^{6}$. This study aims to document the traditional methods of fermenting bamboo shoot by the various tribes in Nagaland and the gastronomy of the Nagas associated with it.

Nagaland embodies the scenic beauty of fields and terrains with a unique culture and traditions. Celebrations eulogizing folk songs and dances occurs throughout the year characterized by ebullient tribes. There are 16 major tribes and several minor tribes inhabiting the 12 districts of Nagaland. For this study, 5-7 households each were selected from Longleng, Kohima, Zunheboto, Phek, Mokokchung, Tuensang, Mon and Wokha districts of the state and the womenfolk were interviewed through questionnaires to document the traditional methods of preparation of bastenga by the various Naga tribes. Data on gastronomy provide cumulative information across the state, where the culinary and ethical values of traditional dishes cooked with bastenga (fermented bamboo shoot) and bamboo shoot have been discussed. 